ENVIRONMENTAL SCIENCES

\title{
A LOW COST WATER TREATMENT BY USING A NATURAL COAGULANT
}

\author{
S.V. Maruti Prasad ${ }^{1}$, B. Srinivasa Rao ${ }^{2}$ \\ ${ }^{1,2}$ Department of Basic Sciences \& Humanities, Aditya Institute of Technology and Management, Tekkali, Srikakulam \\ District, Andhra Pradesh, INDIA,.maru_tkl_2001@yahoo.com;bsraon@gmail.com
}

\begin{abstract}
Ground water is fresh water located in the core space of soil and rocks and water is essential for the survival of human beings. In addition to food, shelter and clothing, water is one of our basic human needs and lack of potable water is a major cause of death and disease in our world. Now a days due to rapid industrialization even in rural areas, water become contaminated. Presently there are no appropriate low cost methods available for removal of water contaminants from drinking water. There are a variety of purification methods of drinking water which are very costly and those methods cannot serve a common man effectively. The purpose of this study is to provide information on low cost household water treatment using seeds of the Drum stick tree. Present study deals with the suitability of coagulation-flocculation process using Moringa Oleifera seeds as natural coagulant for purification of water for drinking purpose. In present study various does of Moringa Oleifera seed powder like 50, 100 and $150 \mathrm{mg} /$ litre were taken and checked for the efficiency dose for various water samples. After treatment of water samples with Morigna Oleifera seed powder were analyzed for the parameters like Turbidity and $\mathrm{pH}$. There is an appreciable change in these parameters and the values are within the range of W.H.O. standards. Application of this low cost Moringa Oleifera seeds is recommended for eco-friendly, non-toxic, simplified water treatment where rural people living in extreme poverty are presently drinking highly turbid and contaminated water.
\end{abstract}

Keywords: Drumstick (Moringa Oleifera), Natural coagulant, water samples, absorbent, coagulant.

\section{INTRODUCTION:}

Drumsticks are consumed almost all over India. The important traditional use of drumsticks that not a lot of people know of water purification what do we do when we get turbid water from taps? We generally boil it, sediment the larger particles and then filter the water using some cloth. This is how it is done in most lower class and even in some middle class homes. However, this wastes lot of cooking gas which is a privilege in most Indian homes. Our ancestors had a simple solution to the problem of water filtration - adding a little bit of powder obtained from drumstick seeds. In a matter of minutes, the drumstick particles bind to the dirt and sediment the dirt down. This process also modifies the other parameters like $\mathrm{pH}$, conductivity and hardness of water.

In this present study an attempt has been made to check how Moringa Oleifera powder changes various properties of drinking water in rural industrially developed areas, so that the water is suitable to drink.

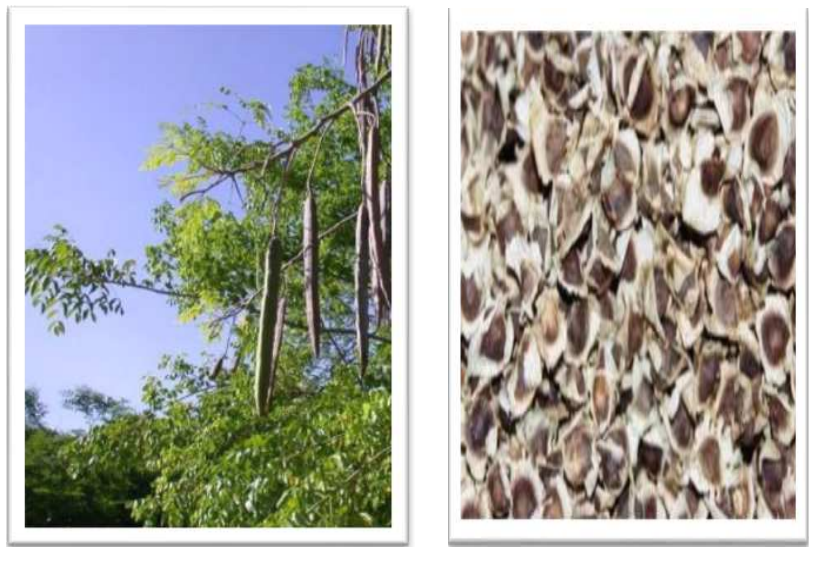

Fig.1 Moringa Oleifera Tree Fig.2 Moringa Oleifera Seeds

\section{MATERIALS AND METHODS:}

\subsection{Materials}

Moringa Oleifera Seed Powder, water samples collected from Vamsadhara Canal Water (Sample-1), Well water at Ravivalasa Village (Sample-2) near Tekkali, Srikakulam District an industrially developed area where the main sources 
for drinking water are wells and Ground water at AITAM Engineering College, Tekkali (Sample-3) which is a residential area about 4000 students are drinking water every day.

\subsection{Method:}

Good quality Moringa oleifera seeds are taken and removed its wings and coat from their seeds. Fine powder was prepared by using mortar and pestle and this powder was directly used as coagulant. Water samples were collected from Vamsadhara Canal Water (Sample-1), Industrial Area well water at Ravivalasa Village (Sample-2)and Ground water at AITAM Engineering College, Tekkali, (Sample-3), for the study purpose. Water is treated by adding of MoringaOleifera Seed powder directly. The water quality parameters were checked before and after treatment of M.Oleifera. Doses of seed powder were selected as 50, 100 and $150 \mathrm{mg} /$ litre for treatment.

The coagulant was mixed with three water samples individually and kept on the mechanical shaker for $45 \mathrm{~min}$ at $110-120 \mathrm{rpm}$. The settling time was 1-2 hours (depending on the water turbidity of different samples). After sedimentation, supernatant water is separated and the same is taken for test. The water quality parameters were checked before and after the treatment and the efficiency dose of Moringaoleifera seed powder was determined.

\section{RESULTS AND DISCUSSION:}

\subsection{Colour}

Samples 1 and 2 under study have faint brown colour before treatment with MoringaOleifera seed powder. After adding different doses of Moringa to the sample removes colour and the samples are became colorless. This suggests that the MoringaOleifera seeds show absorbent properties. Good clarification is obtained if a small cloth bag filled with the powder seeds of Moringa are swirled round with turbid water. These above observations can show from TABLE-1.

Table-1: Colour of samples $1 \& 2$ before and after treatment with M.O.Seed powder

\begin{tabular}{|l|l|l|l|l|}
\hline \multirow{2}{*}{ Sample } & Before & \multicolumn{3}{|l|}{ After Treatment } \\
\cline { 3 - 5 } & Treatment & $50 \mathrm{mg} / \mathrm{L}$ & $100 \mathrm{mg} / \mathrm{L}$ & $150 \mathrm{mg} / \mathrm{L}$ \\
\hline 1 & $\begin{array}{l}\text { Faint } \\
\text { brown }\end{array}$ & Colourless & Colourless & Colourless \\
\hline 2 & $\begin{array}{l}\text { Faint } \\
\text { brown }\end{array}$ & Colourless & Colourless & Colourless \\
\hline
\end{tabular}

\subsection{Turbidity}

The variation of turbidity in the samples after adding MoringaOleifera Seeds are shown in the graphs and also tabular forms. Canal water (Sample-1) is more turbid than other samples Sample-2 and Sample-3. This turbidity of Sample-1 may be continuous movement of water in the river. Before treatment of MoringaOleifera, turbidity is 113 NTU in Canal water and 15.5 NTU and 14.7 NTU in other samples. In all the samples it was observed that, the adding of M.O. Seed powder, decreases the turbidity with increasing doses.
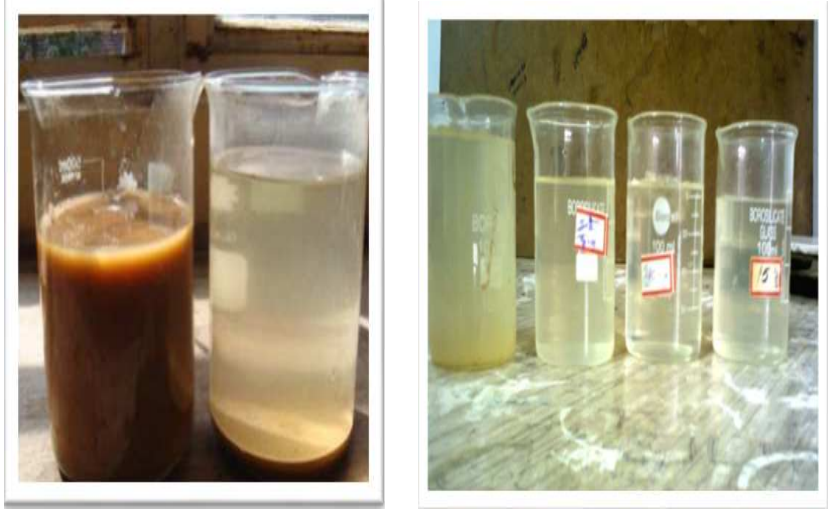

Fig3\&4 decreasing of turbidity with increasing doses of M.O.Powder

Table-2: Turbidity of all three samples Before and After treatment with M.O. Seed powder

\begin{tabular}{|l|l|l|l|l|}
\hline \multirow{2}{*}{ Sample } & Before & \multicolumn{3}{|l|}{ After Treatment } \\
\cline { 3 - 5 } & Treatment & $50 \mathrm{mg} / \mathrm{L}$ & $100 \mathrm{mg} / \mathrm{L}$ & $150 \mathrm{mg} / \mathrm{L}$ \\
\hline 1 & 113 & 66 & 44 & 43 \\
\hline 2 & 15.5 & 9.2 & 8.8 & 8.7 \\
\hline 3 & 14.7 & 9.4 & 9.2 & 8.9 \\
\hline
\end{tabular}

In Samples-2 and 3, it was observed that, the turbidity decrement reaches about uniform for all the added doses. In Sample-1 i.e.,Vamsadhara Canal water the decrement in turbidity is prominent and uniform after adding MoringaOliefera dose of 100mg/litre.

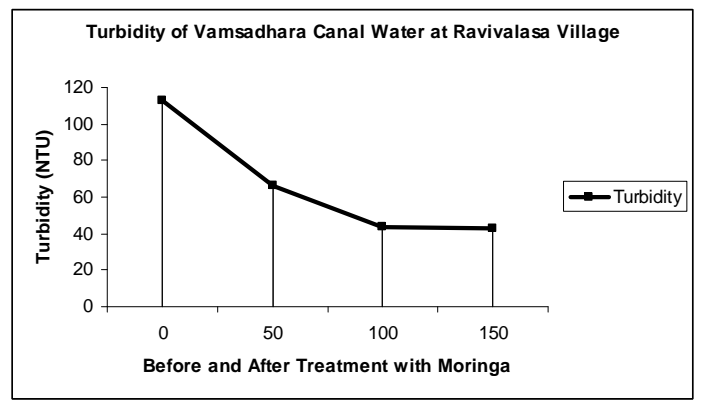




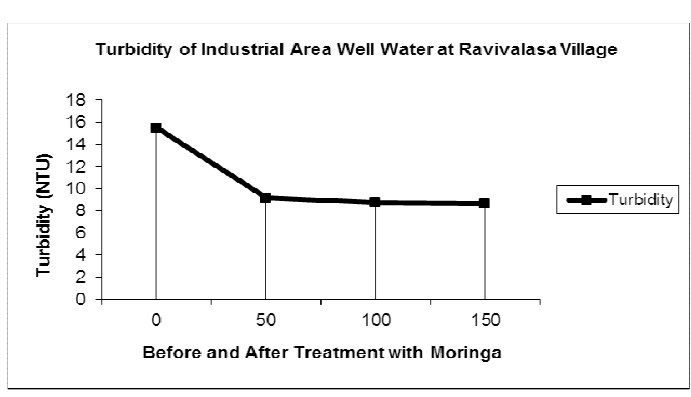

Graph2

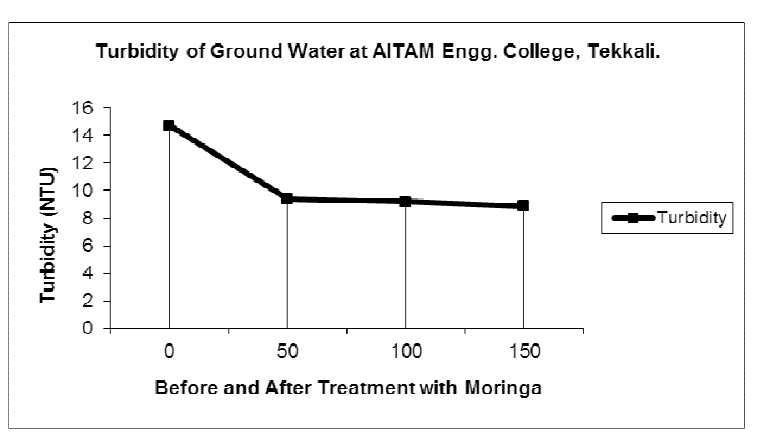

Graph3

The above observation may be due to an improvement in the flock size and flock was settled rapidly. The overdosing resulted in the saturation of the polymer bridge sites and caused destabilization of the destabilized particles due to insufficient number of particles to form more inter-particle bridges. The high positive charge and small size suggest that the main destabilization mechanism may could be adsorption and charge neutralization. It was found that $90-99 \%$ of turbidity in treated water was removed by using M. oleifera seed powder. (Bina B., et al., 2010). These studies are confirmed that the seeds are highly effective in removing suspended particles from water with medium to high levels of turbidity (Moringa seeds are less effective at treating water with low levels of turbidity)

\section{$3.3 \mathrm{P}^{\mathrm{H}}$}

During the present study, treatment of Moringa Oleifera seed powder was given to ground water (Sample 1 and 3) samples in different doses. During the analysis, it was observed that after treatment with Moringa Seed powder, $\mathrm{pH}$ was increased for $50 \mathrm{mg} / \mathrm{L}$ and it was decreased for $100 \mathrm{mg} / \mathrm{L}, 150 \mathrm{mg} / \mathrm{L}$ doses for the above samples. After treatment the $\mathrm{pH}$ range was 7.57 to 7.44 in Sample-2 and 7.35 to 7.15 in Sample-3. In Sample1 and 3 the water was acidic in nature before treatment and it was converted to the basic nature after treatment.

Treatment of MoringaOleifera seed powder was given to Canal water (Sample-1) in different doses. It was observed that before treatment the $\mathrm{pH}$ was 6.3 show acidic properties. After treatment with M.O.Powder, $\mathrm{pH}$ was increased to 7.43 at $50 \mathrm{mg} / \mathrm{L}$ dose but gradually decreased to 7.35 and 7.19 by adding of M.O.powder as $100 \mathrm{mg} / \mathrm{L}$ and $150 \mathrm{mg} / \mathrm{L}$ respectively. After treatment the range of $\mathrm{pH}$ in Sample-1 was 7.43 to 7.19 and it is within the limit of W.H.O. Standards.

The recommended acceptable range of $\mathrm{pH}$ for drinking water specified by W.H.O. was 6.0 to 8.0. (W.H.O. 2006). The treatments gave a $\mathrm{pH}$ range of 7.57 to 7.19 which falls within the reducing trends on the concentration of the dosing solutions were increased. In some doses $\mathrm{pH}$ increases with increasing concentrations of Moringa as coagulant. It was reported that the action of M.O. as a coagulant lies in the presence of water soluble cationic proteins in the seeds. This suggests that in water, the basic amino acids present in the protein of Moringa would accept a proton from water resulting the release of a hydroxyl group making the solution basic (Olayemi A.B. et al., 1994)

Table3: $\mathrm{pH}$ of all three samples before and after treatment with M.O.Seed powder

\begin{tabular}{|l|l|l|l|l|}
\hline \multirow{2}{*}{ Sample } & \multirow{2}{*}{$\begin{array}{l}\text { Before } \\
\text { Treatment }\end{array}$} & \multicolumn{4}{|l|}{ After Treatment } \\
\cline { 3 - 5 } & $50 \mathrm{mg} / \mathrm{L}$ & $100 \mathrm{mg} / \mathrm{L}$ & $150 \mathrm{mg} / \mathrm{L}$ \\
\hline 1 & 6.3 & 7.43 & 7.35 & 7.19 \\
\hline 2 & 7.4 & 7.57 & 7.56 & 7.44 \\
\hline 3 & 6.65 & 7.35 & 7.26 & 7.15 \\
\hline
\end{tabular}

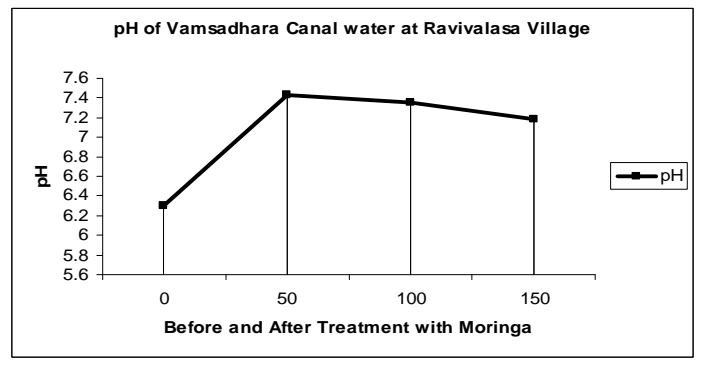

Graph4

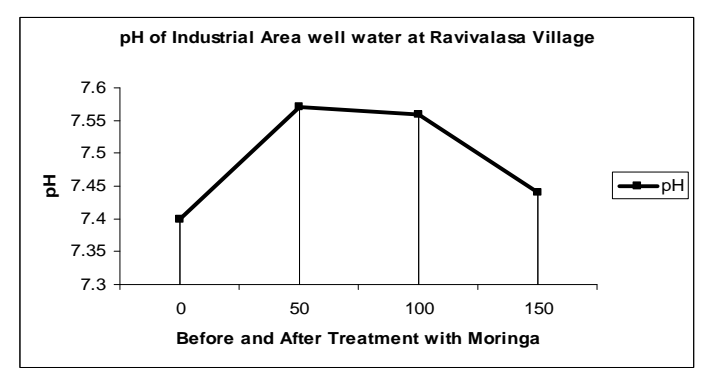

Graph5 


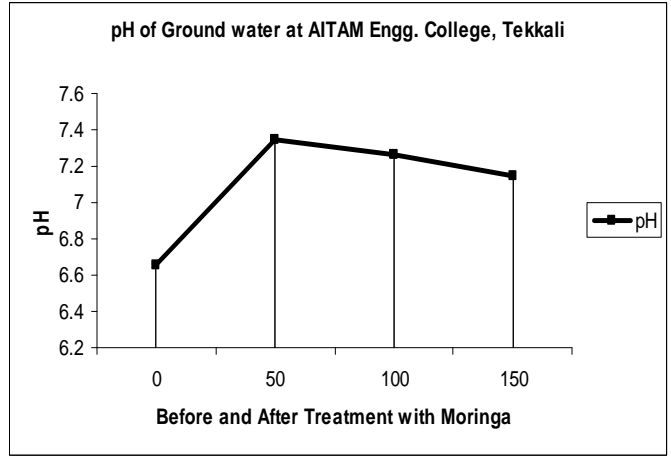

Graph6

\section{CONCLUSIONS}

The results obtained show that the powder from seed kernels of $\mathrm{M}$. oleifera contains some coagulating properties and acts as a flocculent, absorbent for the treatment of drinking water at loading doses of $50 \mathrm{mg} / \mathrm{L}, 100 \mathrm{mg} / \mathrm{L}$ and $150 \mathrm{mg} / \mathrm{L}$ and above. It reduces the turbidity after treatment. This lends support to earlier findings of the use of powder processed from Moringa seeds as a coagulant in water purification system. Considering the fact that Moringa coagulum can be locally produced, its use in water purification should be encouraged. This is likely to reduce the high cost of the current water treatment systems. The seeds of M.Oleifera exhibited the fastest turbidity and colour removal potential. These studies have also confirmed that the seeds are highly effective in removing suspended particles from water with medium to high levels of turbidity (Moringa seeds are less effective at treating water with low levels of turbidity). M.Oleifera seed is not giving any toxic effect. It is ecofriendly method of purification of water and consequently it is being recommended for large scale water treatment use in the rural industrially developed area where no facilities are available for the treatment of drinking water.

\section{REFERENCES}

[1]Bina B., Mehdinejad M. H., Gunnel Dalhammer, Guna Rajarao, M. Nikaeen and H. Movahedian Attar, Effectiveness of Moringa oleifera coagulant protein as natural coagulant aid in removal of turbidity and bacteria from turbid waters, World Academy of Science, Engineering and Technology, 67, (2010) [2]Folkard G. and Sutherland T., The use of Moringa oleifera as a natural coagulant for water and waste water treatment, Department of engineering, University of Leicester, UK, (2001)

[3]Mangale S. M., Chonde S. G., Jadhav A. S., and Raut P. D. Study of Moringa oleifera (Drumstick) seed as natural Absorbent and Antimicrobial agent for River water treatment, J. Nat. Prod. Plant Resour., 2012, 2 (1):89-100.
[4]Olayemi A.B. and Alabi, R.O. Studies on traditional water purification using $M$. oleifera seed, African study monographs, 15, 101-109 (1994)

[5]Olsen A., Water research , 1987, 21 (3): 517-522.

[6]Suleyman A. Muyibi and Lilian M. Evison, "Moringa oleifera seeds for softening hard water", Department of Civil Engineering, University of Newcastle upon Tyne, Newcastle upon Tyne NEI 7RU, England, Wat. Res. 29(4), 1099-1105 (1994)

[7] WHO (2006). Guideline for drinking-water quality (electronic resources): incorporating first addendum. Vol. 1, Recommendations, 3rd edition Internet: http://www.who.int/water_sanitation_health/dwq/gdwq0506.p df

\section{BIOGRAPHIES:}

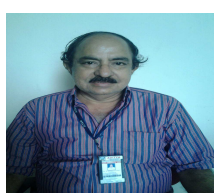

25 years teaching and 10 years research experience with 15 research papers on "Atmospheric Physics". Acted as Board of Studies member for Under Graduation, Andhra University, Department of Physics.

At present working as Professor of Physics, B.S.\&H Department, AITAM, Tekkali, Srikakulam District, Andhra Pradesh. Acting as Board of Studies member for Department of Physics, AITAM, Tekkali

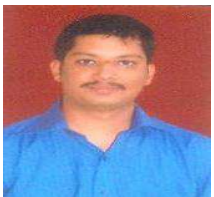

08 years teaching experience with 02 research papers on "Environmental Sciences". Acting as Board of Studies member for Department of Chemistry in AITAM, Tekkali

At present working as Asst. Professor of Chemistry, B.S.\&H Department, AITAM, Tekkali, Srikakulam District, Andhra Pradesh. 